\title{
Rare tuberous sclerosis Case with Typical Presentation of Classical Triad in Adult, JLNMCH, Bhagalpur
}

\author{
Authors \\ Dr Abilesh Kumar ${ }^{1}$, Dr Praveen Suresh Jadhav², Dr Surabhi ${ }^{3}$, \\ Dr Abhishek Tiwari ${ }^{4}$, Dr Pandu Ajmeera ${ }^{5}$ \\ ${ }^{1} \mathrm{MD}$ (Internal Medicine), FICP, Associate Professor, Postgraduate Medicine Department, JLNMCH, \\ Bhagalpur, Bihar \\ 2,3,4,5 MD (Internal Medicine P.G. Student), Postgraduate Medicine Department, JLNMCH, Bhagalpur, Bihar \\ *Corresponding Author \\ Dr Praveen Suresh Jadhav

Abstract
Aim: To study rare tuberous sclerosis with typical presentation.
Methods \& Objectives: Detail study case of genetic disorder tuberous sclerosis with
Clinical features \&radiological findings.
Discussion: We came across tuberous sclerosis with its typical triad of epilepsy, optimal mental status \&
adenoma sebasium in our medicine department, JLNMCH, Bhagalpur.
Conclusion: Tuberous Sclerosis though rarely present with a typical triad is commonly seen in children's
but it can be present with such classical features in adults too.
Keywords: Tuberous sclerosis.

\section{Background}

Tuberous sclerosis complex (TSC) is a genetic disorder affecting cellular differentiation, proliferation, and migration early in development, resulting in a variety of hamartomatous lesions affecting vital organs. Mostly all affected people have skin abnormalities, including patches of unusually light-colored skin, areas of raised and thickened skin, and growths under the nails. Tumors on the face called facial angiofibromas are also common beginning in childhood.

Mutations in the tsc1 or tsc2 gene can cause tuberous sclerosis complex.
The $t s c 1$ and $t s c 2$ genes provide instructions for making the proteins hamartin and tuberin, respectively. Within cells, these two proteins likely work together to help regulate cell growth and size. The proteins act as tumor suppressors, which normally prevent cells from growing and dividing too fast or in an uncontrolled way. Tuberous sclerosis complex has an autosomal dominant pattern of inheritance

\section{Case Details}

18 yrs old male patient XXX brought by his father YYY residing at Itwa, Banka in JLNMCH, Bhagalpur with 
c/o:- convulsions since two days 3-4 times /day; unconsciousness since 1 day

No H/O Trauma, Vomiting, Fever \& Weakness of limbs,

H/O Present Illness

Pt was apparently alright 2days back then he suffered repeated convulsion attacks for two days followed by unconsciousness \& got admitted by father in JLNMCH, Bhagalpur \& becomes conscious after two days of treatment.

H/O Past Illness:

$\mathrm{Pt}$ is a k/c/o epilepsy since 6 years and on antiepileptic drugs since 4 years. even though he is on medications he suffered convulsions intermittently once or twice in a month.

He is not a $\mathrm{k} / \mathrm{c} / \mathrm{o}$ DM, HTN, TB.

$\mathrm{He}$ is not schooling since childhood but active and having good intelligence but as age progresses he looks slightly dull and having lower intelligence than other siblings in family.

He suffered from a rash on face six years back which was gradually increase in size for 2 years \& remains of same size till day, not associated with fever, papular type, butterfly shaped over malar prominence area\& also on chin.

Hypo pigmented patch over upper back appears first $\mathrm{f} / \mathrm{b}$ similar patch on lower back.

Also some granular skin coloured patch in lower back which appears first before convulsions

Family H/O

No similar problems in family.

Pt having one brother and two sisters not suffering from any such problems.

Neither any paternal nor any maternal relatives are affected from similar problems.

Drug /Allergic H/0: Not significant

\section{General Examination}

Pt is conscious, cooperative \& well oriented to time, place, person.

Afebrile; P: 74 beats/min, regular, equal in volume on both sides, no radio-radial or radiofemoral delay, peripheral pulses are palpable.

B.P:120/70 mmhg in supine position on right arm. RR: 18 cycles /min.
NO Pallor, cyanosis, clubbing, icterus, oedema, lymphadenopathy.

\section{Local Examination}

Skin/Face: Facial Angiofibroma/Adenoma

Sebaseum

Rash on face since six years which was gradually increase in size for 2 years $\&$ remains of same size till day, not associated with fever, papular type, butterfly shaped over malar prominence area\& chin
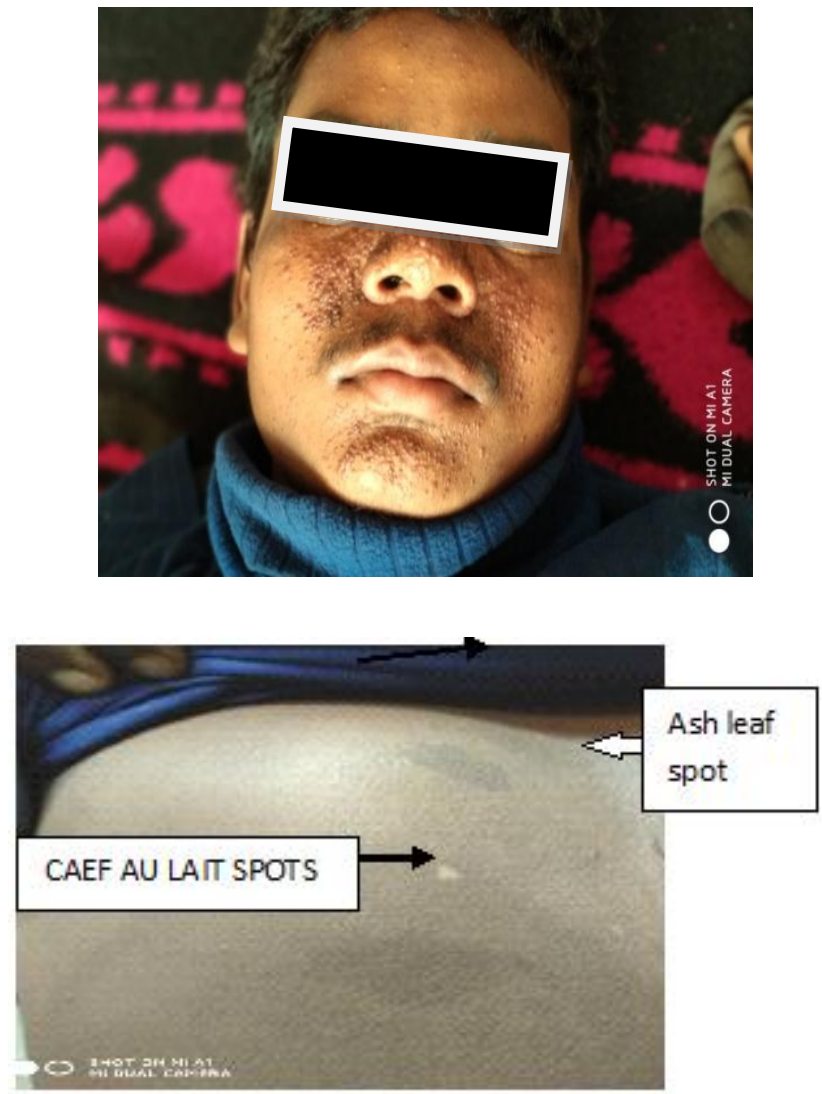

Shagreen Patch \& Ash Leaf Spot

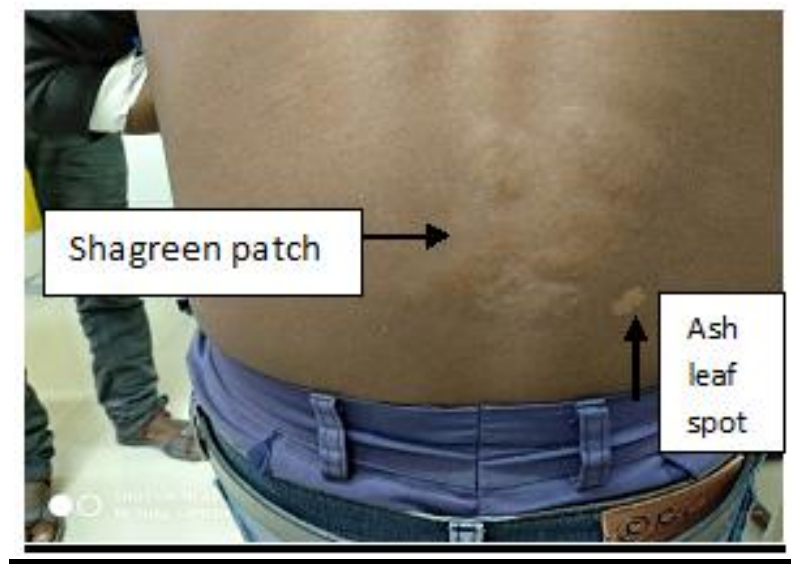



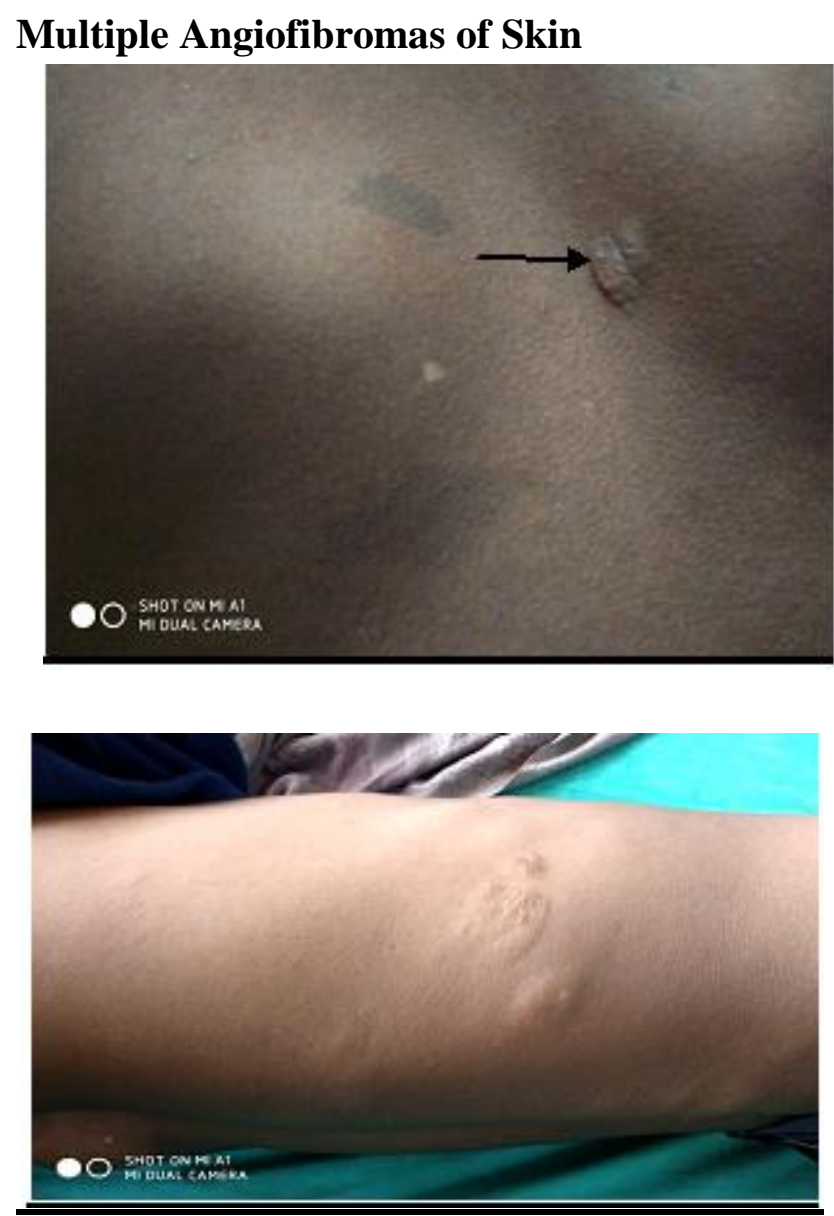

MMSE Score

Total Score: 23/30

[Impression: Mild Cognition Impairment]

Mild: 19-23 Points

Moderate: 10-18 Points

Severe: $\leq 9$

\section{Intelligent Quotient}

$\mathrm{IQ}=$ mental age/chronological age $\times 100$

$\mathrm{IQ}=12 / 18 \times 100$

$=66.66$

Comment: Moderate Mental Retardation

\section{Management}

Echocardiography (ecg): normal; chest xray: normal; ultrasound w/a: normal; usg chest: normal lectroencephalography (eeg): seizure disorder

\section{CT Scan Brain: Plainct Scan Brain: Contrast}

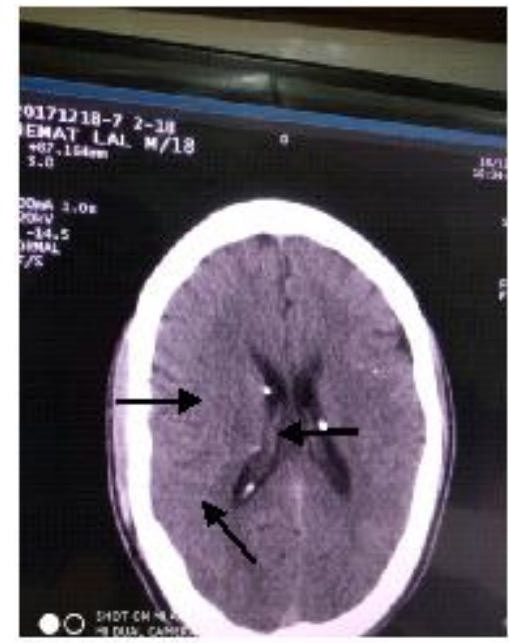

Multiple subependymal Calcified Spot

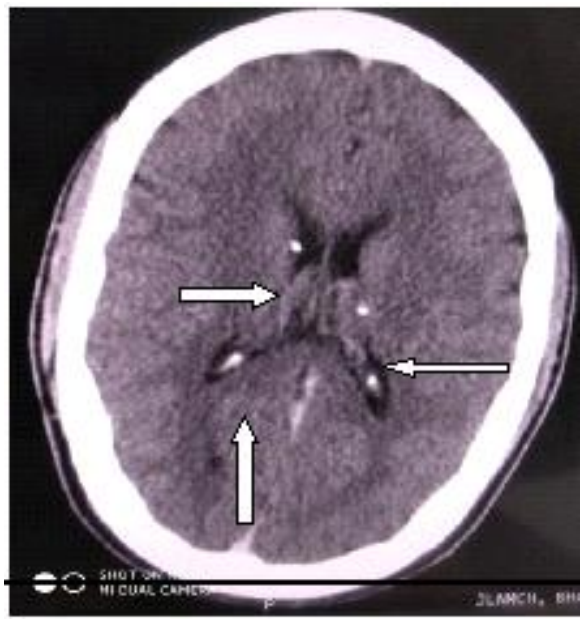

Multiple Calcific Focus Noted In Periventricular Region

\section{MRI Brain}

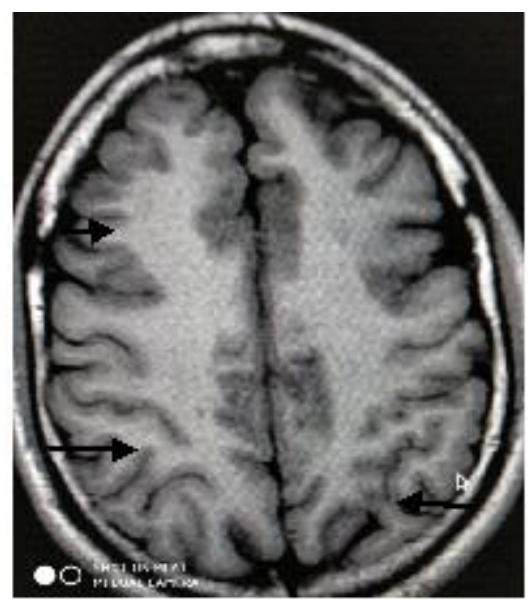

Cortical Tubers 


\section{JMSCR Vol||07||Issue||12||Page 795-799||December}

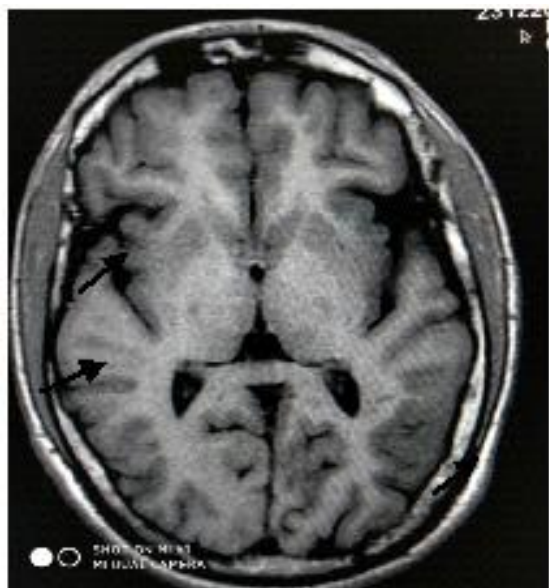

Cortical Tubers

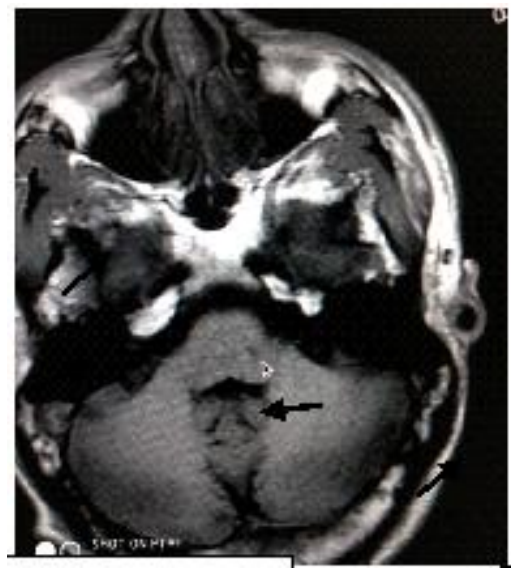

Cerebellar Tubers

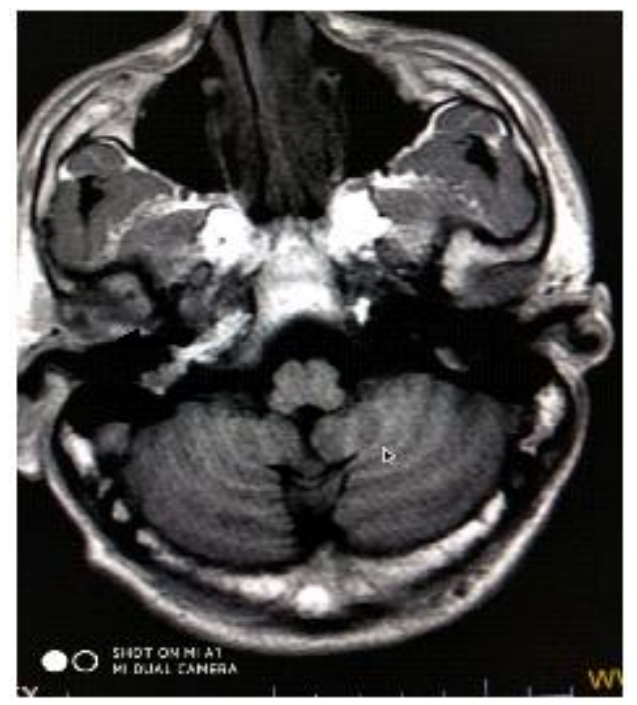

Cerebellar Tubers

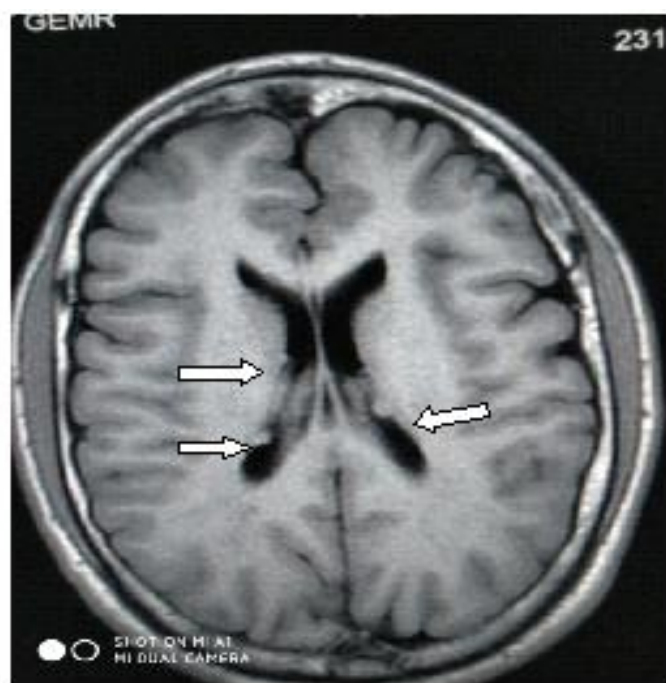

Subependymal Nodules

\section{Findings}

Subependymal nodule along both lateral ventricles,showing hyperintense signal on $\mathrm{T} 1 \mathrm{~W}$ \&hypointence signal on T2W/FLAIR and subtle enhancement on post GAD images.

Focal areas of altered signal in bilateral cerebral hemisphere,predominantly in bilateral frontal \& left postero-temporal lobe in cortical /subcortical region,showing hyperintense signal on T2W/FLAIR with no evidence of restriction on DWI or blooming on GRE images.

Impression: CEMRI brain reveals subependymal nodules along both lateral ventricles with cortical/subcortical tubers in bilateral cerebral hemisphere----suggestive of TUBEROUS SCLEROSIS

\section{Treatment}

Antiepileptic drugs are given to control convulsions and symptomatically treated.

\section{Conclusion}

- Characteristic vogt's triad of TUBEROUS SCLEROSIS consisting of epilepsy,low intelligence \& adenoma sebacium (EPILOIA) is present in this patient.

- Skin manifestations like Hypomelanic macules ("ash leaf spots"), which are white or lighter patches of skin caused by a lack of skin pigment or melanin-the substance that gives skin its color. 
- Reddish spots or bumps called facial angiofibromas (also called adenoma sebaceum), which appear on the face (sometimes resembling acne) and consist of blood vessels and fibrous tissue.

- Areas of thick leathery, pebbly skin called shagreen patch.

- Cortical tubers \& subependymal nodules (SEN) signifies tuberous sclerosis complex on MRI

- Multiple Subependymal calcified spots noted in periventricular area on CT SCAN

- Other organs are within normal limit \& not associated with tumors

\section{References}

1. In: Kasper DL, Fauci AS, Hauser SL, , Longo DL, editors. Harrison's Principles Of Internal Medicine. 19th ed. NewYork, McGraw-Hill: p-344,364,,599t,604,1854.

2. Rao VT, Hegde $\mathrm{T}$, Das $\mathrm{S}$, et al. A clinicopathological study of Tuberous Sclerosis. Neurology India 1986;34:24960.

3. Verma BS, Tailor MH. Familial tuberous sclerosis: A review with report of three cases. Indian Paediatrics 1965;2:401-10.

4. Maxine A. Papadakis, Stephen J McPHEE, Michael W. Rabow. Current medical diagnosis \& treatment; 2016: fifty-fifth Edison: tuberous sclerosis,p-994.

5. Kohrman $\mathrm{MH}$, emergency treatments in the management of tuberous sclerosis complex, pediatr neurol, 2012 May;46(5);267-75

6. YP Munjal, SK Sharma, AK Agarwal, P Gupta: API Textbook of Medicine ;tenth Edison; tuberous sclerosis; p$248 t, 301,2167$
7. Monica P. Islam, E. steve Roach, Robert B. Daroff, Joseph Jankovic, John C. Mazziotta, Scott L. Pomeroy: Bradley's Neurology in clinical practice: seventh Edison: neurocutaneous syndromes: Tuberous sclerosis:p-1538-1543. 